\title{
ANALISIS PENDAPATAN POLA USAHATANI BERBASIS TANAMAN PANGAN DAN PETERNAKAN DI KABUPATEN GROBOGAN
}

\author{
Analysis of Food Crop and Livestock Based Farming System Income \\ in Grobogan District
}

\author{
Siti Rohmatin Wisudawati ${ }^{1)}$, Mukson $^{1)}$, Wiludjeng Roessali ${ }^{1)}$ \\ ${ }^{1)}$ Program Studi Agribisnis Fakultas Peternakan dan Pertanian Universitas Diponegoro \\ Email: sitirohmatinwisudawati@gmail.com
}

\begin{abstract}
This study aimed to analyze income in food crop and livestock based farming system, and to analyze factors influencing farmer's income in Grobogan district. This research was conducted in November to December 2018 in Pulokulon District and Toroh District, Grobogan Regency. The research used survey method by direct interview with a questionnaire guide. Quota sampling was used to determine the number of samples. The number of farmer respondents as samples was 70 people selected by Snowball sampling method. The results of this research shows that there were two patterns of farming system carried out by the respondents including rice-corn-soybean-beef cattle (pattern I) and rice-corn-rice-beef cattle (pattern II). The average income of the farmers with the pattern I was IDR 16,596,380/year under a business scale of 0.32 ha, while the average income in pattern II was lower which was IDR 16,222,162/year under a business scale of 0.30 ha. Based on Independent Sample t-test there was no significant difference between the incomes in pattern I and pattern II. Both the pattern I and the pattern II had the same R/C Ratio of 1.54. The profitability was $53.91 \%$ under the pattern I and $53.74 \%$ under the pattern II. The two farming patterns are feasible because their R/C Ratio > 1 and profitability higher than bank loan interest rate.
\end{abstract}

Keywords: Food Crop, Income, Livestock, Profitability, and R/C Ratio.

\begin{abstract}
ABSTRAK
Penelitian ini bertujuan untuk menganalisis pendapatan pola usahatani berbasis tanaman pangan dan peternakan di Kabupaten Grobogan. Penelitian ini dilaksanakan pada bulan November sampai dengan Desember 2018 di Kecamatan Pulokulon dan Kecamatan Toroh, Kabupaten Grobogan. Metode penelitian menggunakan metode survei dengan melakukan wawancara langsung menggunakan panduan kuesioner. Metode penentuan jumlah sampel yang digunakan yaitu Quota Sampling. Petani responden sebagai sampel berjumlah 70 orang dan diambil dengan metode Snowball Sampling. Hasil penelitian menunjukkan bahwa terdapat dua pola usahatani yang dijalankan responden, pola I yaitu padi-jagung-kedelai-sapi dan pola II yaitu padi-jagung-padi-sapi. Rata-rata pendapatan usahatani dengan pola I adalah $\mathrm{Rp} 16.596 .380,-/$ tahun pada skala usaha 0,32 ha, sedangkan rata-rata pendapatan usahatani dengan pola II lebih rendah yaitu Rp 16.222.162,/tahun pada skala usaha 0,30 ha. R/C Rasio pola I dan pola II yaitu 1,54. Profitabilitas usahatani pola I yaitu $53,91 \%$ dan profitabilitas pola II yaitu $53,74 \%$. Nilai R/C Rasio dan profitabilitas menunjukkan bahwa kedua pola usahatani tersebut layak dijalankan dan profitable, karena nilai R/C Rasio > 1 dan profitabilitas lebih tinggi dibandingkan dengan tingkat suku bunga kredit bank.
\end{abstract}

Kata kunci: Pendapatan, Profitabilitas, R/C Rasio Tanaman Pangan, dan Ternak. 


\section{PENDAHULUAN}

Sektor pertanian mempunyai peranan penting dalam perekonomian nasional, terutama pada perekonomian rakyat (Fuglie, 2004; Khairiyakh, Irham, \& Mulyo, 2016). Pertanian merupakan sektor strategis sekaligus sektor yang paling banyak menyerap tenaga kerja dan berbasis pedesaan karena sebagian besar penduduk tinggal di wilayah pedesaan dan bermata pencaharian sebagai petani (Handayani, Irwan, \& Begem, 2017). Kontribusi sektor pertanian terhadap Produk Domestik Bruto (PDB) nasional tahun 2017 mencapai 18\% dengan rata-rata pertumbuhan sekitar 9,71\% pada 2012 hingga 2016 (Badan Pusat Statistik, 2017a).

Usaha di sektor pertanian di bedakan menjadi 5 sub sektor yaitu tanaman pangan, perkebunan, kehutanan, perikanan dan peternakan (Barokah, Rahayu, \& Sundari, 2014). Padi, jagung dan kedelai saat ini menjadi komoditas tanaman pangan utama yang menjadi bahan makanan pokok masyarakat, banyak diusahakan oleh petani dan menjadi sumber pendapatan utama petani di Indonesia.Pembangunan pertanian khususnya tanaman pangan bertujuan meningkatkan produksi dan memperluas penganekaragaman hasil pertanian (Handayani et al., 2017).

Salah satu upaya untuk meningkatkan produktivitas tanaman pangan yaitu dengan melakukan pola tanam atau pergiliran tanaman (Rajagukguk, Febryano, \& Herwanti, 2018; Rusastra, Saliem, Supriyati, \& Saptana, 2016). Pola tanam (croppingpattern) merupakan usaha penanaman pada sebidang lahan dengan mengatur susunan tata letak dan urutan tanaman selama periode waktu tertentu (Osama, Elkholy, \& Kansoh, 2017; Sugihardjo, Sutrisno, Setyono, \& Suntoro, 2018). Pergiliran tanaman (crop rotation) merupakan penanaman dua jenis tanaman atau lebih yang dilakukan secara bergiliran pada lahan yang sama dalam periode waktu tertentu (Nayak, 2016; Neamatollahi,
Vafabakhshi, Jahansuz, \& Sharifzadeh, 2017) Pola tanam diterapkan dengan tujuan untuk memanfaatkan sumber daya secara optimal serta menghindari resiko kegagalan (Nuryanti dan Kasim, 2017). Rotasi tanaman yang dilakukan oleh petani tidak selalu sama antara satu petani dengan petani yang lain (Liebman \& Dyck, 1993; Thenail et al., 2009). Hal tersebut memungkinkan adanya perbedaan pendapatan yang diperoleh antar petani. Selain tanaman pangan, sumber pendapatan petani juga berasal dari ternak yang dipelihara (Assefa et al., 2014; Dawson \& Goldberger, 2008) Petani biasanya memiliki ternak dalam jumlah sedikit, namun turut menyumbang pedapatan yang diperoleh petani. Oleh karena itu, baik tanaman pangan ataupun ternak sangat berkontribusi terhadap pendapatan usahatani (Lammerts van Bueren et al., 2011; Louwaars, 2018)

Kabupaten Grobogan adalah salah satu daerah di Jawa Tengah yang mengembangkan usahatani tanaman pangan dengan melakukan pola rotasi tanaman dan memiliki hasil produksi yang cukup tinggi. Produksi tanaman pangan di Kabupaten Grobogan pada tahun 2016 yaitu 799 ton padi, 700 ton jagung dan 48 ton kedelai (Badan Pusat Statistik, 2017b). Selain bertani, pada umumnya petani di Kabupaten Grobogan juga menjadi peternak guna meningkatkan pendapatan. Setiap rumah tangga petani di Kabupaten Grobogan pada umumnya memelihara ternak yaitu sapi potong.Tahun 2016 jumlah populasi sapi potong di Kabupaten Grobogan yaitu 187.660 ekor, jumlah populasi tersebut terbesar kedua di Provinsi Jawa Tengah (Badan Pusat Statistik, 2017b). Adanya ternak yang dimiliki petani serta penerapan pola rotasi tanaman yang berbeda menyebabkan pendapatan yang diperoleh antara petani satu dan lainnya dapat pula berbeda, selain itu kelayakan dari usaha yang dijalankan oleh petani perlu dikaji lebih lanjut dari sisi pendapatan. Oleh karena itu diperlukan analisis mengenai pendapatan secara terperinci sehingga dapat 
menjadi bahan pertimbangan bagi petani dalam menjalankan usahataninya.

Penelitian ini bertujuan untuk menganalisis pendapatan, R/C Rasio, dan profitabilitas (Bhullar \& Gupta, 2017; Monahan, 2018) usahatani berbasis tanaman pangan dan peternak di Kabupaten Grobogan. Manfaat penelitian ini bagi petani dapat digunakanan sebagai bahan pertimbangan dalam menjalankan usahataninya, bagi pemerintah dapat digunakan sebagai bahan pertimbangan dalam menentukan kebijakan terkait bidang pertanian, bagi peneliti lain dapat digunakan sebagai sumber informasi dan perbandingan bagi penelitian selanjutnya.

\section{METODE PENELITIAN}

Penelitian ini dilaksanakan pada bulan November sampai dengan Desember 2019 di Kecamatan Pulokulon dan Kecamatan Toroh, Kabupaten Grobogan. Penetapan lokasi berdasarkan pertimbangan bahwa lokasi tersebut merupakan kecamatan di Kabupaten Grobogan yang memiliki kombinasi produksi yang paling tinggi untuk tiap komoditas tanaman pangan serta memiliki jumlah populasi sapi potong yang tinggi. Metode penelitian menggunakan metode survei. Metode penentuan sampel menggunakan quota sampling dengan jumlah responden sebanyak 70 orang, dimana 35 responden dari Kecamatan Pulokulon dan 35 responden dari Kecamatan Toroh. Pengambilan responden menggunakan teknik snowball sampling. Data yang diperoleh yaitu data primer dan data sekunder.Data primer diperoleh dari hasil wawancara kepada responden dengan bantuan kuesioner.Data Sekunder diperoleh dari literatur yang terkait dengan penelitian.

Analisis data dalam penelitian ini digunakan analisis perhitungan biaya ekonomi meliputi biaya produksi, penerimaan, pendapatan, R/C Rasio dan profitabilitas. Selain itu data dianalisis dengan uji beda One Sample t-Test dan Independent Sample t-Test yang sebelumnya telah dilakukan uji Normalitas data menggunakan aplikasi Statistical Package for the Social Sciences (SPSS) (Plume, 2003; Qureshi, 2012). Perhitungan pendapatan usahatani dilakukan dengan menggunakan rumus(Brookes \& Barfoot, 2017; Ryś-Jurek, 2018) yang mengacu pada sebagai berikut:

$$
\begin{aligned}
& \mathrm{TC}=\mathrm{FC}+\mathrm{V} \\
& \mathrm{TR}=\mathrm{P} \times \mathrm{Y} \\
& \Pi=\mathrm{TR}-\mathrm{TC} \\
& \mathrm{R} / \mathrm{C} \text { Ratio }=\frac{\mathrm{TR}}{\mathrm{TC}} \\
& \text { Profitabilitas }=\frac{\Pi}{\mathrm{TC}} \times 100 \%
\end{aligned}
$$

Keterangan :

$\pi \quad=$ Pendapatan usahatani tanaman pangan dan sapi potong (Rp/tahun)

$\mathrm{TR}=$ Total penerimaan $(\mathrm{Rp} / \mathrm{tahun})$

$\mathrm{TC}=$ Total biaya (Rp/tahun)

$\mathrm{P} \quad=\operatorname{Harga}(\mathrm{Rp} / \mathrm{kg})$

$\mathrm{Y} \quad=$ Kuantitas produksi (kg/tahun)

$\mathrm{FC} \quad=$ Biaya tetap (Rp/tahun)

$\mathrm{VC}=$ Biaya variabel (Rp/tahun)

\section{HASIL DAN PEMBAHASAN}

\section{Keadaan Umum Lokasi Penelitian.}

Kabupaten Grobogan terletak di Provinsi Jawa Tengah, memiliki luas wilayah $1.975,86 \mathrm{Km}^{2}$ yang terdiri dari 19 kecamatan dan 280 desa/ kelurahan. Kecamatan Toroh memiliki luas daerah $119,32 \mathrm{~km}^{2}$ dengan luas lahan sawah 4.330,00 ha dan tegalan seluas 1.927,48 ha. Kecamatan Pulokulon memiliki luas daerah $133,64 \mathrm{~km}^{2}$ dengan luas lahan sawah $5.675,49$ ha dan tegalan $1.393,30$ ha. Luas lahan sawah di Kecamatan Pulokulon digolongkan menjadi dua yaitu sawah irigasi seluas 0,80 ha dan sawah tadah hujan seluas 5.674,69 ha (Badan Pusat Statistik, 2017c).

Mayoritas petani di Kabupaten Grobogan membudidayakan tanaman pangan dan memelihara ternak sapi potong.Kecamatan Toroh dan Kecamatan Pulokulon merupakan kecamatan dengan kombinasi produksi tanaman pangan dan populasi ternak sapi potong yang tinggi di Kabupaten Grobogan. Kecamatan Toroh 
memiliki rata-rata produksi padi 49,64 $\mathrm{kw} / \mathrm{ha}$, jagung 53,30 kw/ha, kedelai 21,07 $\mathrm{kw} / \mathrm{ha}$ dan memiliki populasi sapi potong sebanyak 16.166 ekor. Kecamatan Pulokulon memiliki rata-rata produksi padi $52,18 \mathrm{kw} / \mathrm{ha}$, jagung $58,22 \mathrm{kw} / \mathrm{ha}$, kedelai
24,48 $\mathrm{kw} / \mathrm{ha}$ dan populasi sapi potong sebanyak 18.858 ekor (Badan Pusat Statistik, 2017).

Identitas Responden. Karakteristik petani responden dapat dilihat pada Tabel 1.

Tabel 1. Karakteristik Responden

\begin{tabular}{|c|c|c|c|c|c|}
\hline \multirow{2}{*}{ No. } & \multirow{2}{*}{ Keterangan } & \multicolumn{2}{|c|}{ Kecamatan Pulokulon } & \multicolumn{2}{|c|}{ Kecamatan Toroh } \\
\hline & & Jumlah & Persentase & Jumlah & Persentase \\
\hline & & ---jiwa-- & ---\%--- & --jiwa-- & ----\%---- \\
\hline \multirow[t]{5}{*}{1} & Kelompok Umur & & & & \\
\hline & $21-40$ & 7 & 20,00 & 5 & 14,29 \\
\hline & $41-60$ & 23 & 65,71 & 22 & 62,86 \\
\hline & $61-80$ & 5 & 14,29 & 8 & 22,86 \\
\hline & Jumlah & 35 & 100,00 & 35 & 100,00 \\
\hline \multirow[t]{6}{*}{2} & Tingkat Pendidikan & & & & \\
\hline & SMA & 0 & 0,00 & 1 & 2,86 \\
\hline & SMP & 13 & 37,14 & 9 & 25,71 \\
\hline & SD & 19 & 54,29 & 22 & 62,86 \\
\hline & Tidak Tamat & 3 & 8,57 & 3 & 8,57 \\
\hline & Jumlah & 35 & 100 & 35 & 100 \\
\hline \multirow[t]{5}{*}{3} & Lama Bertani & & & & \\
\hline & $1-20$ & 9 & 25,71 & 2 & 5,71 \\
\hline & $21-40$ & 18 & 51,43 & 24 & 68,57 \\
\hline & $41-60$ & 8 & 22,86 & 9 & 25,71 \\
\hline & Jumlah & 35 & 100,00 & 35 & 100,00 \\
\hline \multirow[t]{5}{*}{4} & Jumlah Tanggungan Keluarga & & & & \\
\hline & $1-3$ & 6 & 17,14 & 6 & 17,14 \\
\hline & $4-6$ & 28 & 80,00 & 28 & 80,00 \\
\hline & $\geq 6$ & 1 & 2,86 & 1 & 2,86 \\
\hline & Jumlah & 35 & 100,00 & 35 & 100,00 \\
\hline
\end{tabular}

Sumber: Data Primer Diolah, 2019.

Tabel 2. Rata-Rata Produksi Tanaman Pangan dan Ternak di Kabupaten Grobogan

\begin{tabular}{|c|c|c|c|c|c|c|}
\hline \multirow{2}{*}{ Pola Tanam } & \multirow{2}{*}{$\begin{array}{l}\text { Skala Usaha } \\
\text { (ha) }\end{array}$} & \multicolumn{4}{|c|}{ Produksi Tanaman Pangan } & \multirow{2}{*}{$\begin{array}{c}\text { PBBH } \\
\text { Sapi Potong }\end{array}$} \\
\hline & & Padi 1 & Jagung & Kedelai & Padi 2 & \\
\hline & & \multicolumn{4}{|c|}{ - } & --kg/hari-- \\
\hline P-J-K-S (1) & 0,32 & 1.527 & 1.320 & 956 & & 0,69 \\
\hline P-J-P-S (2) & 0,30 & 1.450 & 1.270 & & 1.450 & 0,68 \\
\hline
\end{tabular}

*PBBH (Pertambahan Bobot Badan Harian)

Sumber: Data Primer Diolah, 2019. 
Responden di Kecamatan Pulokulon mayoritas memiliki usia 41-60 tahun sebesar $65,71 \%$ dengan tingkat pendidikan Sekolah Dasar (SD) yaitu sebesar 54,29\%, pengalaman bertani 21-40 tahun sebesar $51,43 \%$ dan memiliki tanggungan keluarga 4-6 jiwa sebesar $80,00 \%$. Begitu pula di Kecamatan Toroh mayoritas responden memiliki usia 41-60 tahun yaitu sebesar $62,86 \%$ dengan tingkat pendidikan Sekolah Dasar (SD) sebesar $62,86 \%$, pengalaman bertani $21-40$ tahun sebesar $68,57 \%$ dan memiliki tanggungan keluarga sebanyak 4-6 jiwa yaitu sebesar $80 \%$.

\section{Kondisi Usahatani Tanaman Pangan dan}

Ternak. Berdasarkan hasil penelitian diketahui bahwa jenis tanaman pangan yang dikembangkan oleh petani di Kabupaten Grobogan adalah padi, jagung dan kedelai. Pola rotasi yang diterapkan di Kecamatan Pulokulon adalah padi-jagung-kedelai, sedangkan pola rotasi di Kecamatan Toroh adalah padi-jagung-padi. Jenis padi yang banyak dibudidayakan oleh petani responden adalah ciherang, petani menyukai padi jenis ini karena mampu beradaptasi pada berbagai kondisi, mampu menghasilkan bulir yang lebih banyak dibanding varietas lain dan umurnya relatif lebih singkat yaitu 110-115 hari. Varietas jagung yang banyak diusahakan oleh petani responden adalah jagung P18 dan P21. Petani menyukai jagung dengan jenis tersebut karena memiliki perakaran yang kokoh, tahan terhadap kekeringan, tongkol yang dihasilkan terisi penuh dan jenggelnya kecil. Jenis kedelai yang diusahakan oleh petani responden yaitu kedelai Malabar versi Grobogan. Kedelai jenis tersebut banyak dibudidayakan petani karena umur tanam yang relatif singkat yaitu 72 hari, sebelum dipanen daun sudah rontok terlebih dahulu, hasil panen benar-benar kering sehingga petani tidak perlu menjemur terlalu lama. Petani di Kecamatan Pulokulon membudidayakan tanaman pangan pada rata-rata luas lahan 0,32 ha sedangkan petani di Kecamatan Toroh membudidayakan tanaman pangan pada rata-rata luas lahan 0,30 ha.
Petani di Kabupaten Grobogan khususnya Kecamatan Pulokulon dan Kecamatan Toroh selain mengusahakan berbagai jenis tanaman pangan, mereka juga mengusahakan ternak sapi potong. Jenis sapi potong yang banyak dipelihara petani adalah Sapi Brahman dan Sapi Jawa. Petani memelihara ternak sapi potong dengan metode penggemukan dengan tujuan untuk meningkatkan pendapatan yang mereka peroleh, karena meskipun dalam jumlah yang sedikit usaha ternak sapi potong rakyat turut menyumbang pendapatan yang diperoleh petani. Hal ini sesuai pendapat Rusdiana et al. (2010) yang menyatakan bahwa sapi potong memiliki peran yang kompleks dalam sistem pertanian baik dari fungsi ekonomi ataupun biologis dalam meningkatkan pendapatan petani. Petani di Kecamatan Pulokulon dan Kecamatan Toroh memelihara ternak sapi potong dalam skala kecil, hanya mengandalkan tenaga kerja keluarga dan pakan dari sisa hasil pertanian atau rumput lapang. Hal tersebut sesuai pendapat Suryana (2009) yang menyatakan bahwa profil usaha ternak sapi potong di Indonesia umumnya menerapkan sistem pemeliharaan tradisional dengan memanfaatkan sumber daya manusia dan pakan yang tersedia, pada umumnya ternak dipelihara dalam skala kecil dengan lahan dan modal terbatas.

Produksi. Produksi merupakan usaha untuk menghasilkan suatu produk yang digunakan untuk memenuhi kebutuhan manusi (Ntaribi \& Paul, 2018; Tseng, Chiu, \& Liang, 2018). Berdasarkan hasil penelitian, diperoleh hasil produksi usahatani tanaman pangan dan ternak seperti pada Tabel 2 diatas.

Berdasarkan Tabel 2, diketahui bahwa jumlah produksi padi dan jagung dengan pola I (padi-jagung-kedelai-sapi) lebih tinggi dibandingkan pola II (padijagung-padi). Produksi padi pada pola 1 sebesar $1.527 \mathrm{~kg} / \mathrm{mt}$, sedangkan produksi padi pada pola 2 sebesar $1.450 \mathrm{~kg} / \mathrm{mt}$. Produksi jagung pola 1 yaitu $1.318 \mathrm{~kg} / \mathrm{mt}$, sedangkan produksi jagung pola 2 yaitu $1.270 \mathrm{~kg} / \mathrm{mt}$. Produksi kedelai pola 1 yaitu 
$959 \mathrm{~kg} / \mathrm{mt}$. Produksi padi musim tanam kedua pada pola 2 yaitu $1.450 \mathrm{~kg} / \mathrm{mt}$. Petani di Kecamatan Pulokulon yang menerapkan pola tanam 1 memiliki rata-rata luas lahan 0,32 ha, sedangkan petani di Kecamatan Toroh yang menerapkan pola tanam 2 memiliki rata-rata luas lahan 0,30 ha. Adanya perbedaan luas lahan ini dapat mempengaruhi jumlah produksi tanaman pangan yang dihasilkan.Hal tersebut sesuai pendapat Sugiartiningsih (2012) bahwa luas lahan berpengaruh positif terhadap produksi jagung.

Rata-rata jumlah produksi padi, jagung dan kedelai per hektar di Kabupaten Grobogan berturut-turut yaitu $4.801 \mathrm{~kg} / \mathrm{ha}$, $4.177 \mathrm{~kg} / \mathrm{ha}$ dan $2.987 \mathrm{~kg} / \mathrm{ha}$. Jumlah produksi padi dan kedelai tersebut lebih tinggi jika dibandingkan hasil penelitian Siregar (2018) bahwa rata-rata jumlah produksi padi, jagung dan kedelai di Kecamatan Kumpeh Kabupaten Jambi tahun 2017 berturut-turut yaitu $3.389 \mathrm{~kg} / \mathrm{ha}$, $5104 \mathrm{~kg} / \mathrm{ha}$ dan $1.162 \mathrm{~kg} / \mathrm{ha}$. Perbedaan jumlah produksi antar pola tanam dapat disebabkan oleh berbagai faktor, diantaranya yaitu skala usaha yang berbeda, jenis benih, serta banyaknya penggunaan pupuk.

Pertambahan bobot badan harian $(\mathrm{PBBH})$ ternak sapi potong di Kabupaten Grobogan tergolong cukup rendah, dimana rata-rata PBBH sapi potong di Kecamatan Pulokulon dengan pola tanam padi-jagungkedelai-sapi adalah 0,69 kg/hari dan ratarata $\mathrm{PBBH}$ sapi potong di Kecamatan Toroh dengan pola tanam padi-jagung-padi-sapi adalah $0,68 \mathrm{~kg} / \mathrm{hari}$. Jenis sapi yang diusahakan oleh responden yaitu sapi brahman dan sapi jawa, dengan bobot awal sapi rata-rata $191,8 \mathrm{~kg}$. $\mathrm{PBBH}$ dalam penelitian ini lebih rendah jika dibandingkan hasil penelitian Firdausi et al. (2012) yang mana rata-rata PBBH sapi brahman cross pada bobot badan yang berbeda adalah 1,22 kg/hari. Namun demikian $\mathrm{PBBH}$ sapi pada penelitian ini lebih tinggi dibandingkan hasil penelitian Adiwinarti et al. (2011) yang mana rata-rata PBBH sapi jawa sebesar $0,63 \mathrm{~kg} / \mathrm{hari}$. Perbedaan tersebut dapat terjadi karena adanya perbedaan bangsa dan manajemen pemberian pakan yang berbeda, sesuai dengan pendapat Sundari et al. (2009) yang menyatakan bahwa faktor-faktor yang mempengaruhi produksi sapi potong adalah jenis bangsanya, umur, kualitas dan kuantitas pakan hijauan maupun konsentrat serta penanggulangan penyakit. Jenis pakan yang diberikan pada penelitian ini yaitu jerami padi, rumput lapang dan beberapa pakan tambahan lain seperti dedak dan garam, tanpa memberikan pakan tambahan konsentrat.

Biaya Produksi. Biaya produksi merupakan suatu beban yang harus ditanggung oleh produsen untuk melakukan proses produksi (Brookes \& Barfoot, 2017; Guo et al., 2017) Biaya peoduksi usahatani berbasis tanaman pangan dan peternakan dengan pola padi - jagung - kedelai - sapi dapat dilihat pada Tabel 3.

Berdasarkan Tabel 3, diketahui bahwa total biaya produksi padi-jagungkedelai yaitu Rp 7.036.508,-/tahun dengan rata-rata skala usaha 0,32 ha atau setara dengan Rp 21.989.087,-/ha/tahun. Biaya produksi tanaman pangan tersebut lebih rendah dibandingkan total biaya produksi jagung-padi-kacang tanah pada penelitian Dharmaningtyas (2011) yaitu Rp 22.620.990,/ha/tahun. Hal tersebut dapat disebabkan oleh adanya perbedaan penggunaan input produksi seperti benih, pupuk ataupun pestisida. Total biaya produksi ternak pada penelitian ini yaitu Rp 21.329.806,/ekor/tahun, lebih besar dibandingkan ratarata biaya produksi sapi potong pada penelitian Wahyono et al. (2018) yaitu Rp 10.595.800,-/ekor/tahun. Adanya perbedaan tersebut dapat disebabkan oleh perbedaan penggunaan faktor produksi seperti bangsa sapi, lama pemeliharaan dan pakan.

Rata-rata total biaya produksi pada pola usahatani padi-jagung-kedelai dan sapi adalah Rp. 35.618.449,-/tahun. Nilai Tersebut lebih besar jika dibandingkan dengan biaya produksi usahatani dan sapi potong pada penelitian Wahyono et al. (2018) dengan pola tanam padi-jagung 
dan sapi potong dimana biaya produksinya sebesar Rp 29.795.950.000,-/tahun. Hal tersebut dikarenakan adanya perbedaan jumlah musim tanam, dimana pada penelitian ini terdapat tiga kali musim tanam dalam satu tahun, sedangkan pada penelitian pembanding hanya dua kali musim tanam dalam satu tahun.

Tabel 3. Rata-Rata Biaya Produksi Pola Usahatani Padi-Jagung-Kedelai-Sapi

\begin{tabular}{|c|c|c|c|c|c|}
\hline \multirow{2}{*}{ No } & \multirow{2}{*}{ Uraian } & \multicolumn{3}{|c|}{ Tanaman Pangan } & \multirow{2}{*}{$\begin{array}{c}\text { Ternak } \\
\text { Sapi }\end{array}$} \\
\hline & & Padi & Jagung & Kedelai & \\
\hline \multirow{4}{*}{1} & & \multicolumn{3}{|c|}{-------------Rp/mt------------- } & ---Rp/thn--- \\
\hline & $\begin{array}{l}\text { Biaya Tetap } \\
\text { - PBB } \\
\text { - Sewa Lahan }\end{array}$ & $\begin{array}{r}20.819 \\
200.000\end{array}$ & $\begin{array}{r}20.819 \\
200.000\end{array}$ & $\begin{array}{r}20.819 \\
200.000\end{array}$ & 2.190 \\
\hline & $\begin{array}{l}\text { - Penyusutan } \\
\text { - Iuran Anggota } \\
\text { - Sewa Traktor }\end{array}$ & $\begin{array}{r}40.708 \\
5.000 \\
160.286\end{array}$ & $\begin{array}{r}40.708 \\
5.000\end{array}$ & $\begin{array}{r}40.708 \\
5.000\end{array}$ & 105.965 \\
\hline & $\begin{array}{l}\text { - Biaya Listrik } \\
\text { Biava Variabel }\end{array}$ & & & & 58.286 \\
\hline \multirow{9}{*}{2} & - Biaya Benih & 147.200 & 332.874 & 192.000 & \\
\hline & - Biaya Pupuk & 524.876 & $\begin{array}{r}454.020 \\
50.255\end{array}$ & 351.393 & \\
\hline & - Biaya Pestisida & $\begin{array}{r}71.712 \\
1318521\end{array}$ & $\begin{array}{r}50.355 \\
1067700\end{array}$ & $\begin{array}{r}43.161 \\
1419241\end{array}$ & 4.820 .357 \\
\hline & - Biaya Transportasi & 34.071 & 34.714 & 34.714 & \\
\hline & - Biaya Bakalan & & & & 20.842 .857 \\
\hline & Biaya Pakan Membeli & & & & 2.707 .200 \\
\hline & Biaya Obat-obatan & & & & 4.800 \\
\hline & Biaya Lainnya & & & & 40.286 \\
\hline & Total Biaya Produksi & 2.523 .192 & 2.206 .280 & 2.307 .036 & 28.581 .941 \\
\hline
\end{tabular}

Sumber: Data Primer Diolah, 2019.

Tabel 4. Rata-Rata Biaya Produksi Pola Usahatani Padi-Jagung-Padi-Sapi

\begin{tabular}{|c|c|c|c|c|c|}
\hline \multirow{2}{*}{ No } & \multirow{2}{*}{ Variabel } & \multicolumn{3}{|c|}{ Tanaman Pangan } & \multirow{2}{*}{$\begin{array}{c}\text { Ternak } \\
\text { Sapi }\end{array}$} \\
\hline & & Padi 1 & Jagung & Padi 2 & \\
\hline \multirow{9}{*}{1} & & \multicolumn{3}{|c|}{ 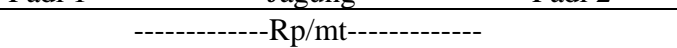 } & --Rp/thn-- \\
\hline & Biaya Tetap & & & & \\
\hline & PBB & 21.886 & 21.886 & 21.886 & 2.391 \\
\hline & Sewa Lahan & 76.190 & 76.190 & 76.190 & \\
\hline & Penyusutan & 39.681 & 39.681 & 39.681 & 171.115 \\
\hline & Iuran Anggota & 40.000 & 40.000 & 40.000 & \\
\hline & Sewa Traktor & 144.257 & & 144.257 & \\
\hline & Biaya Irigasi & & & 606.571 & \\
\hline & Biaya Listrik & & & & 60.000 \\
\hline \multirow[t]{11}{*}{2} & Biaya Variabel & & & & \\
\hline & Biaya Benih & 150.286 & 327.971 & 150.286 & \\
\hline & Biaya Pupuk & 498.473 & 430.601 & 498.473 & \\
\hline & Biaya Pestisida & 66.672 & 47.768 & 1.324 .129 & \\
\hline & Upah Tenaga Kerja & 1.309 .315 & 1.085 .434 & 30.329 & 4.820 .357 \\
\hline & Biaya Transportasi & 31.214 & 33.000 & 30.329 & \\
\hline & Biaya Bakalan & & & & 17.068.571 \\
\hline & Biaya Pakan Membeli & & & & 2.694 .857 \\
\hline & Biaya Obat-obatan & & & & 2.571 \\
\hline & Biaya Lainnya & & & & 40.286 \\
\hline & Total Biaya Produksi & 2.377 .975 & 2.102 .531 & 2.962 .130 & 24.860 .150 \\
\hline
\end{tabular}

Sumber: Data Primer Diolah, 2019. 
Berdasarkan Tabel 4, diketahui bahwa rata-rata biaya tetap pada pola usahatani padi-jagung-padi dan sapi yaitu Rp 1.599.472,-/tahun, yang terdiri dari biaya tetap tanaman pangan Rp 1.428.357, /tahun dan biaya tetap ternak sapi potong yaitu Rp 171.115,-/tahun. Jumlah tersebut lebih besar dibandingkan dengan jumlah biaya tetap pola usahatani padi-jagungkedelai dan sapi, hal tersebut dikarenakan pada pola usahatani padi-jagung-padi dan sapi terdapat biaya tambahan berupa biaya irigasi dan traktor pada tanaman padi musim tanam ketiga.

Rata-rata biaya variabel pada pola usahatani padi-jagung-padi dan sapi yaitu Rp 30.640.921,-/tahun, yang terdiri dari biaya variabel tanaman pangan $\mathrm{Rp}$ 6.014.279,-/tahun dan biaya variabel sapi potong $\mathrm{Rp}$ 24.626.643,-/tahun. Jumlah tersebut lebih kecil dibandingkan dengan biaya variabel pola tanam padi-jagungkedelai dan sapi. Total biaya produksi pada pola tanam padi-jagung-padi dan sapi yaitu $\mathrm{Rp}$ 32.240.394,-/tahun, tidak berbeda terlalu jauh dari total biaya produksi pola tanam padi-jagung-kedelai dan sapi yaitu Rp 34.492.142,-/tahun.

Penerimaan. Penerimaan merupakan sejumlah uang yang diterima dari hasil penjualan produk yang dihasilkan petani. (Altmaier, 2019; Grayson, 1951). Penerimaan dapat diperoleh dari perkalian antara jumlah produksi dengan harga jual. Rata-rata penerimaan usahatani responden dapat dilihat pada Tabel 5.

Berdasarkan Tabel 5, diketahui bahwa penerimaan dari usahatani tanaman pangan dengan pola tanam padi-jagungkedelai adalah Rp 17.275.457,-/tahun, lebih rendah dibandingkan penerimaan usahatani tanaman pangan dengan pola tanam padijagung-padi yaitu Rp 17.773.962,/tahun.Penerimaan usahatani tanaman pangan dengan kedua pola tersebut lebih besar dibandingkan hasil penelitian Dharmaningtyas (2011) dimana penerimaan usahatani dengan pola tanam jagung-padikacang tanah yaitu Rp 27.263.030,-/tahun.
Perbedaan tersebut dapat terjadi karena skala usaha dan jenis tanaman yang diusahakan berbeda.

Total penerimaan pola tanam padijagung-kedelai dan sapi yaitu Rp 52.214.829,-/tahun, lebih tinggi dari total penerimaan dengan pola tanam padijagung-padi dan sapi yaitu $R p$ 48.462.556,/tahun. Total penerimaan kedua pola usahatani di Kabupaten Grobogan tersebut lebih besar dibandingkan dengan penerimaan usahatani di Kabupaten Jember dengan pola usahatani yang sama yaitu tanaman pangan dan sapi potong pada hasil penelitian Wahyono et al. (2018) bahwa penerimaan pola usahatani padi - jagung dan sapi potong yaitu Rp 42.970.000,- per tahun. Hal tersebut dikarenakan pada penelitian pembanding hanya terdapat dua kali musim tanam dalam satu tahun, sehingga total produksi yang dihasilkan lebih rendah dan berpengaruh pada penerimaan yang diperoleh.

Pendapatan. Pendapatan merupakan sejumlah uang yang diterima petani dari hasil usahatani yang diperoleh dari jumlah uang yang diterima dikurangi biaya yang dikeluarkan untuk usahatani yang dilaksanakan (Barker, 2010; Daly, 2017). Rata-rata pendapatan usahatani berbasis tanaman pangan dan peternakan dapat dilihat pada Tabel 6 .

Berdasarkan Tabel 6, diketahui bahwa Rata-rata pendapatan yang diperoleh petani dengan pola usahatani padi-jagungkedelai dan sapi adalah Rp 16.596.380,/tahun, sedangkan rata-rata pendapatan yang diperoleh petani dengan pola usahatani padi-jagung-padi dan sapi lebih rendah yaitu $\mathrm{Rp}$ 16.159.771,-/tahun. Pendapatan pola I lebih besar dibandingkan pola II dapat disebabkan oleh luas lahan yang berbeda, dimana rata-rata luas lahan pola I yaitu 0,32 ha lebih besar di bandingkan luas lahan pola II yaitu 0,30 ha. Semakin luas lahan maka pendapatan yang diperoleh akan semakin tinggi. Hal tersebut sesuai pendapat Mamondol dan Sabe (2016) bahwa terdapat hubungan yang positif dan 
signifikan antara luas lahan dan pendapatan usahatani. Pendapatan kedua pola usahatani tersebut lebih besar jika dibandingkan hasil penelitian Wahyono et al. (2018) di Kabupaten Jember dengan pola tanam padi-padi dan sapi potong diperoleh pendapatan sebesar Rp 16.020.000,-/tahun dan pola tanam padi-jagung dan sapi potong diperoleh pendapatan sebesar $\mathrm{Rp}$ 13.173.000,-/tahun. Perbedaan tersebut dapat disebabkan karena adanya perbedaan jenis tanaman dan jenis sapi yang diusahakan.

Hasil pendapatan dari usaha tanaman pangan rata-rata sebesar $\mathrm{Rp}$ 10.285.137,-/tahun dan rata-rata pendapatan dari ternak sapi potong $\mathrm{Rp}$ 6.092.938,/tahun.Hal tersebut menunjukkan bahwa pendapatan yang diperoleh petani tertinggi adalah dari usaha tanaman pangan karena usaha pokok yang dijalankan oleh petani pada penelitian ini adalah pertanian tanaman pangan. Hal ini sejalan dengan hasil penelitian Adawiyah dan Rusdiana (2016) bahwa keuntungan yang diperoleh petani tertinggi dari usaha tanaman pangan sedangkan usaha ternak sebagai usaha diversifikasi dari usaha tanaman pangan dan sebagai pengisi waktu luang petani dari usaha pokok pertanian. Meskipun bukan penyumbang pendapatan tertinggi bagi petani, namun usaha ternak sapi potong ikut memiliki peran dalam meningkatkan pendapatan yang diperoleh petani.Hal tersebut sesuai dengan pendapat Rusdiana et al. (2010) yang menyatakan bahwa sapi potong memiliki peran dalam sistem pertanian baik dari fungsi ekonomi ataupun biologis dalam meningkatkan pendapatan petani.

R/C Rasio dan Profitabilitas. R/C Rasio merupakan nilai pebandingan antara penerimaan dan biaya yang dikeluarkan selama pelaksanaan usahatani (AkbenSelcuk, 2016; Nishanthini \& Nimalathasan, 2014) Berdasarkan Tabel 6, diketahui bahwa nilai R/C Rasio pola I dan pola II adalah 1,54 yang artinya 1 rupiah uang yang dikeluarkan untuk kegiatan usahatani akan menghasilkan penerimaan sebesar 1,54 rupiah, nilai tersebut menunjukkan bahwa petani memperoleh keuntungan sebesar 0,54 rupiah. R/C Rasio pada penelitian ini lebih tinggi dibandingkan hasil penelitian Wahyono et al. (2018) pada pola tanam padi-padi dan sapi potong diperoleh nilai R/C Rasio sebesar 1,47 dan pada pola tanam padi-jagung dan sapi potong diperoleh nilai R/C Rasio 1,48, namun nilai tersebut lebih rendah jika dibandingkan dengan hasil penelitian Nuryanti dan Kasim (2017) pada pola rotasi tanaman padijagung-jagung dengan nilai R/C Rasio sebesar 2,01. Nilai R/C Rasio lebih besar dari 1 memiliki arti bahwa kedua pola usahatani tersebut menguntungkan atau tidak merugi. Hal tersebut sesuai dengan pendapat Soekartawi (2011) bahwa usahatani dapat dikatakan layak jika memiliki R/C Ratio lebih besar dari satu.

Profitabilitas merupakan kemampuan suatu usaha dalam menghasilkan keuntungan. Berdasarkan Tabel 6, diketahui bahwa ratarata profitabilitas pola usahatani padijagung- kedelai-sapi yaitu sebesar 53,91\%, lebih tinggi dari rata-rata profitabilitas pola usahatani padi-jagung-padi-sapi yaitu sebesar 53,74\%. Profitabilitas adalah kemampuan suatu usaha dalam menghasilkan laba atau keuntungan, maka dapat disimpulkan bahwa pola usahatani padijagung-padi dan sapi potong memiliki kemampuan menghasilkan laba yang lebih tinggi dibandingkan pola usahatani padijagung-kedelai dan sapi potong. Kedua nilai profitabilitas tersebut lebih tinggi dibandingkan dengan suku bunga deposito bank yaitu $6 \%$ sehingga dapat disimpulkan bahwa usahatani berbasis tanaman pangan dan peternakan yang dijalankan oleh petani di Kabupaten Grobogan menguntungkan.

Hasil Uji One Sample t-Test. Uji One Sample t-Test pada penelitian ini digunakan untuk membandingkan nilai R/C Rasio usahatani tanaman pangan dan ternak dengan standar nilai R/C Rasio yaitu 1 . Berdasarkan uji yang telah dilakukan, diperoleh hasil bahwa terdapat perbedaan yang nyata antara nilai R/C Rasio usahatani terhadap nilai 1 . Nilai R/C Rasio usahatani 
yang dijalankan lebih tinggi dibandingkan dengan nilai 1 , menunjukkan bahwa usahatani tersebut layak untuk dijalankan karena menguntungkan. Uji One Sample tTest selanjutnya digunakan untuk membandingkan perbedaan antara nilai profitabilitas dengan suku bunga kredit bank yaitu $6,00 \%$. Hasil uji menunjukkan bahwa terdapat perbedaan yang nyata antara profitabilitas pola usahatani padi-jagungkedelai-sapi dan pola usahatani padijagung-padi-sapi terhadap nilai suku bunga kredit bank. Nilai profitabilitas kedua pola usahatani tersebut berbeda dengan tingkat suku bunga bank dikarenakan profitabilitas usahatani lebih tinggi dibandingkan dengan suku bunga bank.Perbedaan tersebut menunjukkan bahwa usahatani yang dilaksanakan menguntungkan.

Hasil Uji Independent Sample t-Test. Uji Independent Sample t-Test (Kim, 2015; Sedgwick, 2010). Pada penelitian ini digunakan untuk membandingkan pendapatan pola usahatani padi-jagung-kedelai-sapi dan pendapatan pola usahatani padi-jagungpadi-sapi. Hasil uji menunjukkan bahwa nilai Sig. 0,749. Nilai Sig. tersebut lebih besar dari 0,05 yang artinya tidak ada perbedaan yang nyata antara pendapatan pola usahatani padi-jagung-kedelai-sapi dan pendapatan pola usahatani padi-jagungpadi-sapi. Secara uji statistik, tidak terdapat perbedaan yang nyata antara pendapatan pola usahatani padi-jagung-kedelai-sapi dan pendapatan pola usahatani padi-jagungpadi-sapi, namun secara absolut rata-rata pendapatan pola usahatani padi-jagungkedelai-sapi lebih besar dibandingkan dengan pendapatan pola usahatani padijagung-padi-sapi dengan selisih $\mathrm{Rp}$ 436.609,-. Perbedaan tersebut disebabkan oleh adanya perbedaan jenis tanaman yang diusahakan serta perbedaan skala usaha, dimana rata-rata luas lahan pola usahatani padi-jagung-kedelai-sapi adalah 0,32 ha lebih tinggi dibandingkan rata-rata luas lahan pola usahatani padi-jagung-padi-sapi yaitu 0,30 ha.

Tabel 5. Rata-rata Penerimaan Pola Usahatani Tanaman Pangan dan Ternak di Kabupaten Grobogan.

\begin{tabular}{|c|c|c|c|c|}
\hline No & Komoditas & Produksi & Harga Jual & Total \\
\hline & & -----Kg----- & ----Rp/kg---- & ----Rp/thn---- \\
\hline \multirow[t]{8}{*}{1} & P-J-K-S & & & \\
\hline & Padi & $1.527,43$ & 4.700 & 7.178 .914 \\
\hline & Jagung & $1.320,86$ & 3.300 & 4.358 .829 \\
\hline & Kedelai & 956,29 & 6.000 & 5.737 .714 \\
\hline & Sapi & & & \\
\hline & Penjualan Ternak & & & 34.603 .657 \\
\hline & Kotoran Ternak & & & 335.714 \\
\hline & Total Penerimaan & & & 52.214 .829 \\
\hline \multirow[t]{8}{*}{2} & P-J-P-S & & & \\
\hline & Padi 1 & $1.450,29$ & 4.683 & 6.791 .481 \\
\hline & Jagung & $1.270,00$ & 3.300 & 4.191 .000 \\
\hline & Padi 2 & $1.450,29$ & 4.683 & 6.791 .481 \\
\hline & Sapi & & & \\
\hline & Penjualan Ternak & & & 30.285 .737 \\
\hline & Kotoran Ternak & & & 402.857 \\
\hline & Total Penerimaan & & & 48.462 .556 \\
\hline
\end{tabular}

Sumber: Data Primer Diolah, 2019. 
Tabel 6. Rata-Rata Pendapatan Pola Usahatani Padi-Jagung-Kedelai-Sapi dan Padi-Jagung-PadiSapi.

\begin{tabular}{llrrrrr}
\hline \multirow{2}{*}{ No } & $\begin{array}{c}\text { Pola } \\
\text { Usahatani }\end{array}$ & \multicolumn{1}{c}{ Penerimaan } & Biaya Produksi & Pendapatan & $\begin{array}{c}\text { R/C } \\
\text { Rasio }\end{array}$ & Persentase \\
\hline & & $----------------------R p / t a h u n--------------------$ & & $----\%----$ \\
1 & P-J-K-S & 52.214 .829 & 35.618 .449 & 16.596 .380 & 1,54 & 53,91 \\
& - Padi & 7.178 .914 & 2.523 .192 & 4.655 .722 & 2,85 & 184,52 \\
& - Jagung & 4.358 .829 & 2.206 .280 & 2.152 .548 & 1,98 & 97,56 \\
& - Kedelai & 5.737 .714 & 2.307 .036 & 3.430 .679 & 2,49 & 148,71 \\
- Sapi & 34.939 .371 & 28.581 .941 & 6.357 .431 & 1,22 & 22,24 \\
P-J-P-S & 48.462 .556 & 32.302 .785 & 16.159 .771 & 1,54 & 53,74 \\
& - Padi 1 & 6.791 .481 & 2.377 .975 & 4.413 .506 & 2,86 & 185,60 \\
& - Jagung & 4.191 .000 & 2.102 .531 & 2.088 .469 & 1,99 & 99,33 \\
& - Padi 2 & 6.791 .481 & 2.962 .130 & 3.829 .351 & 2,29 & 129,28 \\
& - Sapi & 30.688 .594 & 24.860 .150 & 5.828 .445 & 1,23 & 23,44 \\
\hline
\end{tabular}

Sumber: Data Primer Diolah, 2019.

\section{KESIMPULAN DAN SARAN}

Simpulan. Berdasarkan hasil penelitian yang telah dilakukan, dapat disimpulkan bahwa rata-rata pendapatan usahatani dengan pola padi-jagung-kedelai-sapi yaitu Rp 16.596.380,-/tahun pada skala usaha 0,32 ha, lebih tinggi dibandingkan dengan rata-rata pendapatan usahatani dengan pola padi-jagung-padi-sapi yaitu Rp 16.222.162,/tahun pada skala usaha 0,30 ha. Usahatani berbasis tanaman pangan dan peternakan di Kabupaten Grobogan layak untuk dijalankan dan menguntungkan karena nilai $\mathrm{R} / \mathrm{C}$ rasio lebih dari 1 dan nilai profitabilitas lebih tinggi dari suku bunga kredit bank.Tidak terdapat perbedaan yang nyata antara pendapatan usahatani dengan pola padi-jagung-kedelai-sapi dan pendapatan usahatani dengan pola padi-jagung-padisapi, meskipun secara absolut nilai pendapatan usahatani dengan pola padijagung-kedelai-sapi lebih tinggi.

Saran. Sebaiknya petani berani untuk mengikuti perkembangan teknologi di bidang pertanian, sehingga hasil produksi dapat meningkat.Selain itu dalam menjalankan usaha penggemukan sapi potong, sebaiknya petani perlu memberikan pakan tambahan konsentrat dan suplemen agar ternak terhindar dari penyakit dan produksinya tinggi, selain itu sebaiknya pemeliharaan tidak dilakukan dalam periode waktu yang terlalu lama agar biaya produksi tidak terlalu tinggi.

\section{DAFTAR PUSTAKA}

Adawiyah, C. R. dan S. Rusdiana. 2016. Usahatani Tanaman Pangan Dan Peternakan Dalam Analisis Ekonomi Di Petani Di Pedesaan. J. Riset Agribisnis \& Peternakan, 1(2): 37-49.

Adiwinarti, R., U. R. Farha dan C. M. S. Lestari. 2011. Pertumbuhan Sapi Jawa yang diberi pakan jerami padi dan konsentrat dengan level protein berbeda. JITV. 16(4): 260-265.

Akben-Selcuk, E. (2016). DOES FIRM AGE AFFECT PROFITABILITY? EVIDENCE FROM TURKEY. International Journal of Economic Sciences, V(3).

Altmaier, E. M. (2019). Meaning in life. In Promoting Positive Processes After Trauma (pp. 77-87. 
Ambarsari, W., V. D. Y. B. Ismadi dan A. Setiadi. 2014. Analisis Pendapatan Dan Profitabilitas Usahatani Padi (Oryza Sativa) Di Kabupaten Indramayu. J. Agriwiralodra. 6(2): 19-27.

Assefa, T., Sperling, L., Dagne, B., Argaw, W., Tessema, D., \& Beebe, S. (2014). Participatory Plant Breeding with Traders and Farmers for White Pea Bean in Ethiopia. The Journal of Agricultural Education and Extension, 20(5), 497-512.

Badan Pusat Statistik, 2017b. Kabupaten Grobogan Dalam Angka 2017. BPS Kabupaten Grobogan, Grobogan.

Badan Pusat Statistik, 2017c. Kecamatan Pulokulon Dalam Angka 2017. BPS Kabupaten Grobogan, Grobogan.

Badan Pusat Statistik, 2017d. Kecamatan Toroh Dalam Angka2017. BPS Kabupaten Grobogan, Grobogan

Badan Pusat Statistik. 2017a. Provinsi Jawa Tengah dalam Angka 2017. Badan Pusat Statistik, Jawa Tengah.

Barker, R. (2010). On the Definitions of Income, Expenses and Profit in IFRS. Accounting in Europe, 7(2), 147-158.

Barokah, U., Rahayu, W., \& Sundari, T. (2014). Analisis Biaya dan Pendapatan Usahatani Padi di Kabupaten Karanganyar. AGRIC, 26(1), 12-19.

Bhullar, P. S., \& Gupta, P. K. (2017). Empirical Analysis of Determinants of Profitability of Banks: Evidence from Indian Public Sector Banks. International Journal of Accounting and Financial Reporting, 7(2), 404.

Brookes, G., \& Barfoot, P. (2017). Farm income and production impacts of using GM crop technology 1996-2015. GM Crops \& Food, 8(3), 156-193.

Budiartingsih, R., Y. Maulida dan Taryono. 2010. Faktor-Faktor Yang Mempengaruhi Peningkatan Pendapatan Keluarga Petani Melalui Sektor Informal Di Desa Kedaburapat, Kecamatan Rangsang Barat, Kabupaten Bengkalis. J. Ekonomi. 18(1): 79-93.

Daly, M. (2017). Money-Related Meanings and Practices in Low-Income and Poor Families. Sociology, 5l(2), 450-465.

Dawson, J. C., \& Goldberger, J. R. (2008). Assessing farmer interest in participatory plant breeding: Who wants to work with scientists? Renewable Agriculture and Food Systems, 23(03), 177-187.

Dharmaningtyas, K. S. 2011. Analisis Perbedaan Pendapatan Antara Usahatani Pola Rotasi Jagung-Padi-Kacang Tanah Dengan Usahatani Pola Rotasi Padi-Padi-Padi Pada Lahan Sawah Di Kabupaten Sukoharjo (Skripsi). Surakarta: Universitas Sebelas Maret.

Ekowati, T., D. Sumarjono dan E. Prasetyo. 2014. Buku Ajar Usahatani. UPT Undip Press, Semarang.

Firdausi, A., T. Susilawati, M. Nasich dan Kuswati. 2012. Pertambahan Bobot Badan Harian Sapi Brahman Cross Pada Bobot Badan Dan Frame Size Yang Berbeda. J. Ternak Tropika. 13(1): 48-62. 
Fuglie, K. O. (2004). Productivity growth in Indonesian agriculture, 1961-2000. Bulletin of Indonesian Economic Studies, 40(2), 209-225.

Grayson, M. (1951). CONCEPT OF “ACCEPTANCE” IN PHYSICAL REHABILITATION. Journal of the American Medical Association, 145(12), 893.

Guo, X., Tang, J.-W., Yang, J.-T., Ni, G.-W., Zhang, F.-L., \& Chen, S.-X. (2017). Development of a Practical Enzymatic Process for Preparation of ( $S$ )-2-Chloro-1-(3,4difluorophenyl)ethanol. Organic Process Research \& Development, 21(10), 1595-1601.

Handayani, S. A., Irwan, E., \& Begem, V. (2017). Produksi dan Pendapatan Usahatani Padi di Desa Pujo Asri Kecamatan Trimurjo Kabupaten Lampung Tengah. JIIA, 5(4), 422-429.

Khairiyakh, R., Irham, I., \& Mulyo, J. H. (2016). Contribution of Agricultural Sector and Sub Sectors on Indonesian Economy. Ilmu Pertanian (Agricultural Science), 18(3), 150.

Kim, T. K. (2015). T test as a parametric statistic. Korean Journal of Anesthesiology, 68(6), 540.

Lammerts van Bueren, E. T., Jones, S. S., Tamm, L., Murphy, K. M., Myers, J. R., Leifert, C., \& Messmer, M. M. (2011). The need to breed crop varieties suitable for organic farming, using wheat, tomato and broccoli as examples: A review. NJAS - Wageningen Journal of Life Sciences, 58(3-4), 193-205.

Liebman, M., \& Dyck, E. (1993). Crop Rotation and Intercropping Strategies for Weed Management. Ecological Applications, 3(1), 92-122.

Louwaars, N. P. (2018). Plant breeding and diversity: A troubled relationship? Euphytica, 214(7).

Mamondol, M. R. dan F. Sabe. 2016. Pengaruh Luas Lahan Terhadap Penerimaan, Biaya Produksi Dan Pendapatan Usahatani Padi Sawah di Desa Toinasa Kecamatan Pamona Barat. J. Envira. 1(2): 48-59.

Monahan, S. J. (2018). Financial Statement Analysis and Earnings Forecasting. Foundations and Trends ${ }^{\circledR}$ in Accounting, 12(2), 105-215.

Nishanthini, A., \& Nimalathasan, B. (2014). Determinants of profitability: a case study of listed manufacturing companies in Sri Lanka. Journal of Management, 8(1), 42.

Ntaribi, T., \& Paul, D. I. (2018). Status of Jatropha plants farming for biodiesel production in Rwanda. Energy for Sustainable Development, 47, 133-142.

Nuryanti, D. M. dan N. N. Kasim. 2017. Analisis Pendapatan Usahatani Pola Rotasi Tanaman Padi-Jagung Manis Di Desa Mulyasari Kecamatan Sukamaju. J. TABARO. 1(2): 95-104.

Osama, S., Elkholy, M., \& Kansoh, R. M. (2017). Optimization of the cropping pattern in Egypt. Alexandria Engineering Journal, 56(4), 557-566.

Plume, M. L. (2003). SPSS (Statistical Package for the Social Sciences). In Encyclopedia of Information Systems (pp. 187-196).

Qureshi, F. (2012). Introduction to Statistics with SPSS for Social Science (1st ed.).

Rajagukguk, C. P., Febryano, I. G., \& Herwanti, S. (2018). Perubahan Komposisi Jenis Tanaman dan Pola Tanam pada Pengelolaan Agroforestri Damar. Jurnal Sylva Lestari, 6(3), 18.

Rukka, H. dan A. Wahab. 2013. Faktor-Faktor Yang Mempengaruhi Motivasi Petani Dalam Pelaksanaan Kegiatan P2BN Di Kecamatan Barru, Kabupaten Barru. J. Agrisitem. 9(1): 
$46-56$.

Rusastra, I. W., Saliem, H. P., Supriyati, N., \& Saptana, N. (2016). Prospek Pengembangan Pola Tanam dan Diversifikasi Tanaman Pangan di Indonesia. Forum Penelitian Agro Ekonomi, 22(1), 37.

Rusdiana, S., B. Wibowo dan L. Prahani. 2010. Penyerapan Sumberdaya Manusia Dalam Analisis Fungsi Usaha Penggemukan Sapi Potong Rakyat Di Pedesaan. Prosiding Seminar Nasional Peternakan Dan Veteriner Puslitbangnak Bogor, 453-460.

Ryś-Jurek, R. (2018). FAMILY FARM INCOME AND THEIR PRODUCTION AND ECONOMIC DETERMINANTS ACCORDING TO THE ECONOMIC SIZE IN THE EU COUNTRIES IN 2004-2015.

Sedgwick, P. (2010). Independent samples t test. BMJ, 340(may18 2), c2673-c2673.

Siregar, P. A. 2018. Analisis komparasi pendapatan usahatani padi, jagung, kedelai di Kecamatan Kumpeh Kabupaten Muaro Jambi. Jurnal Fakultas Pertanian Universitas Jambi, 1-12.

Soekartawi. 2011. Ilmu Usaha Tani. Jakarta: Universitas Indonesia.

Sugiartiningsih. 2012. Pengaruh Luas Lahan, Terhadap Produksi Jagung Di Indonesia Periode 1990-2006. J. Ekono Insentif Kopwil4. 6(1): 45-48.

Sugihardjo, Sutrisno, J., Setyono, P., \& Suntoro. (2018). Climate change and farmers' cropping patterns in Cemoro watershed area, Central Java, Indonesia. IOP Conference Series: Earth and Environmental Science, 129, 012033.

Sukayat, H. dan Rumna. 2017. Analisis Pendapatan Dan Faktor-Faktor Sosial Ekonomi Yang Mempengaruhi Hasil Produktivitas Pengelola Usahatani Padi Sawah Kabupaten Cianjur. JIMFE. 3(2): 37-48.

Sundari, A. S. Rejeki dan H. Triatmaja. 2009. Analisis Pendapatan Peternak Sapi Potong Sistem Pemeliharaan Intensif Dan Konvensional Di Kabupaten Sleman Yogyakarta. J. Sains Peternakan. 7(2): 73-79.

Suryana. 2009. Pengembangan Usaha Ternak Sapi Potong Berorientasi Agribisnis Dengan Pola Kemitraan. J. Litbang Pertanian. 28(1): 29-37.

Thenail, C., Joannon, A., Capitaine, M., Souchère, V., Mignolet, C., Schermann, N., ... Baudry, J. (2009). The contribution of crop-rotation organization in farms to crop-mosaic patterning at local landscape scales. Agriculture, Ecosystems \& Environment, 131(3-4), 207-219.

Tseng, M.-L., Chiu, A. S. F., \& Liang, D. (2018). Sustainable consumption and production in business decision-making models. Resources, Conservation and Recycling, 128, 118-121.

Wahyono, N. D., Z. Fanani dan N. Soetjipto. 2018. Analisis Pendapatan Usaha Sapi Potong Dengan Berbagai Pola Tanam Di Kecamatan Umbulsari Kabupaten Jember. J. Nusamba. 3(1): 30-41. 